\title{
Organic effects of associating paclitaxel with a lipid-based nanoparticle system on a nonhuman primate, Cebus apella
}

This article was published in the following Dove Press journal:

International Journal of Nanomedicine

18 May 2017

Number of times this article has been viewed

\section{Danielle Cristinne \\ Azevedo Feio,' Nayara \\ Cristina Lima de Oliveira,' \\ Edmundo Luis Rodrigues \\ Pereira,' Aleksandra \\ Tiemi Morikawa, ${ }^{2}$ José \\ Augusto Pereira Carneiro Muniz, ${ }^{3}$ Raquel Carvalho Montenegro,' Ana Paula Negreiros Nunes Alves, ${ }^{4}$ Patrícia Danielle Lima de Lima, ${ }^{5}$ Raul Cavalcante Maranhão, ${ }^{2}$ Rommel Rodríguez Burbano' \\ 'Human Cytogenetics Laboratory, Institute of Biological Sciences, Federal University of Pará, Belem, ${ }^{2}$ Heart Institute, University of Sao Paulo Medical School Hospital, Sao Paulo, ${ }^{3}$ Evandro Chagas Institute, Primate National Center, Ananindeua, ${ }^{4}$ Department of Clinical Dentistry, Health Sciences Center, Federal University of Ceará, Fortaleza, ${ }^{5}$ Molecular Biology Laboratory, Post Graduate Program of Amazon Parasitic Biology, Biological and Health Sciences Center, State University of Pará, Belem, Brazil}

Correspondence: Danielle Cristinne Azevedo Feio

Human Cytogenetics Laboratory, Institute of Biological Sciences, Federal University of Pará, Augusto Corrêa Street, 0I, Guamá, Belém 66075-II0, PA, Brazil

Tel +559132017102

Fax +55 9l 320। 8I88

Email daniellefeio@yahoo.com.br
Abstract: Lipid-based nanoparticle systems have been used as vehicles for chemotherapeutic agents in experimental cancer treatments. Those systems have generally been credited with attenuating the severe toxicity of chemotherapeutic agents. This study aimed to investigate the effects of associating paclitaxel (PTX) with a lipid-based nanoparticle system on a nonhuman primate, Cebus apella, documenting the toxicity as measured by serum biochemistry, which is a detailed analysis of blood and tissue. Eighteen $C$. apella were studied: three animals were treated with cholesterol-rich nanoemulsion (LDE) only, without PTX, administered intravenously every 3 weeks, during six treatment cycles; six animals were treated with PTX associated with LDE at the same administration scheme, three with lower $\left(175 \mathrm{mg} / \mathrm{m}^{2}\right)$ and three with higher $\left(250 \mathrm{mg} / \mathrm{m}^{2}\right)$ PTX doses; and six animals were treated with commercial PTX, three with the lower and three with the higher doses. In the LDE-PTX group, no clinical toxicity appeared, and the weight-food consumption curve was similar to that of the controls. Two animals treated with commercial PTX presented weight loss, nausea and vomiting, diarrhea, skin flaking, 70\% loss of body hair, and decreased physical activity. The use of LDE as a carrier at both lower and higher doses reduced the toxicity of the drug in this species, which is closely related to human subjects. This was observed not only by clinical, biochemical, and hematological profiles but also by the histopathological analysis. The results of this study support the assumption that lipid-based nanoparticle systems used as drug carriers can serve as valuable tools to decrease the toxicity and increase the safety of chemotherapeutic agents.

Keywords: nanoparticles, LDE, paclitaxel, toxicity, Cebus apella

\section{Introduction}

Advances in cancer research have resulted in the increase of specific knowledge, allowing for new treatments of the disease to be proposed. Lately, the drug-delivery system for cancer has gained prominence in the current medical research. ${ }^{1,2}$ Today, specific targets and targeted treatments are used as alternatives to improve the performance of drugs - of times, ones that are seldom used in clinical practice due to their severe adverse side effects. ${ }^{3}$

In the process of developing systems for cancer-drug delivery, the main focus is no longer on the simple reformulation of drugs for different means of administration, but instead on targeted therapy with an increase in therapeutic drug levels and improvement of treatment selectivity. ${ }^{4}$ These approaches aim to not only complement traditional chemotherapy and radiotherapy but also avoid damage to normal tissue and prevent multiple-drug resistance. ${ }^{4,5}$ 
Nanoemulsion particles resemble low-density lipoproteins (LDLs), which are a normal constituent of blood, as well as being the main vehicle of cholesterol in all tissues. The diameter of spherical nanoparticles ranges from 25 to $50 \mathrm{~nm}$. Each nanoparticle consists of a nucleus made of cholesterol esters with a low proportion of triglycerides encapsulated by a monolayer of phospholipids and free cholesterol (Figure 1). These nanoparticles are manufactured without protein, but acquire apolipoprotein E (APO E) after injection into the bloodstream. APO E adheres to the surface of nanoemulsion particles and connects them to LDL receptors (LDLrs) in the cell membrane. In this way, nanoemulsions are captured and moved to the interior of the cell through receptor-mediated endocytosis..$^{6-8}$

A number of physiochemical and pharmacotechnical studies with a cholesterol-rich nanoemulsion (LDE) system have demonstrated several therapeutic advantages in animal models and clinical trials, including a marked reduction in chemotherapeutic toxicity, allowing for a possible increase in drug dosage while increasing the possibilities for the association of polychemotherapeutic drugs. ${ }^{9-13}$

Incorporation in nanoparticles even protects the drug from chemical degradation in the bloodstream. Possessing these advantages, and being manufactured from lipids present in the organism, these nanoparticles are perfectly integrated into the body's metabolism, operating without immunogenic effects. Employing the LDE system in this way can result in improved quality of life for cancer patients and increase their rates of survival. ${ }^{14-16}$

Paclitaxel (PTX) is an effective and widely used therapeutic drug for the treatment of cancer. It is used in various types of diseases, including ovarian cancer, melanoma, and hepatocellular carcinoma. ${ }^{3}$ However, several cancer patients

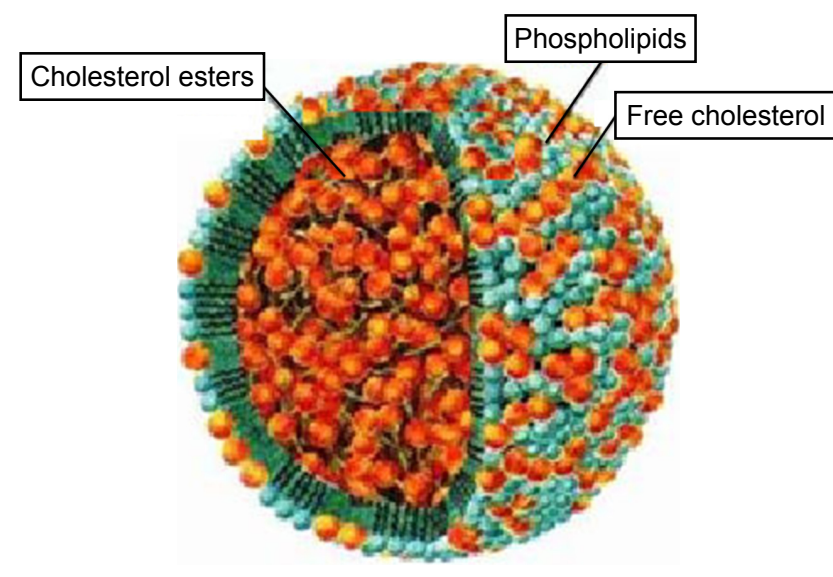

Figure I Design of the LDE particle, demonstrating its structure composed by nucleus made of cholesterol esters encapsulated by a monolayer of phospholipids and free cholesterol.

Abbreviation: LDE, cholesterol-rich nanoemulsion. present both a diminished response to and an increased toxicity resulting from PTX monochemotherapy. It is thus necessary to combine PTX with other substances or incorporate them into carrier products to reach a synergistic blend and a better therapeutic effect. ${ }^{1}$

The use of nonhuman primates as in vivo experimental models is of great importance in work that applies to human health, due to their anatomical, biochemical, and phylogenetic similarity to human primates. Their common traits engender results that can be related as closely and safely as possible to corresponding phenomena in human beings. The size of these animals and their organs also allow for the repetition of diagnostic tests - such as endoscopic exams, collection of blood samples, and biopsies - on a single subject over a long period, and their longevity permits long-term exposure to carcinogens or drugs. ${ }^{17}$

Thus, the objective of the present study was to evaluate tissue and cellular toxicity in nonhuman Cebus apella primates treated with PTX chemotherapy (PTX oleate LDE) and its respective commercial version (Taxol ${ }^{\circledR}$; Bristol-Myers Squibb, New York, NY, USA), comparing the effects on different animals provoked by the different forms of this chemotherapy.

\section{Methodology Animals and treatments}

A total of 18 C. apella, all provided by the National Primate Center (Centro Nacional de Primatas [CENP] is the center's Portuguese name and is located in the north Brazilian state of Pará, which falls within the administrative district of Ananindeua), were evaluated. The animals were kept under the center's standard conditions, having been previously selected and separated for the completion of this work. The animals were handled based on the guidelines for use, maintenance, and welfare of animals, established by the Brazilian federal law on the scientific use of animals (Law 1.1794/2008) and the Normative Resolution of the National Council for the Control of Animal Experimentation CONCEA (no 28, November 13, 2015). Selection was made according to sex (male), weight (3.5-5 kg), age (young adult), and nonparticipation in previous studies. This work was approved by the Research Ethics Committee of Federal University of Pará (UFPA) - CEPAE/BIO008-11, as well as received authorization for activities with a scientific purpose issued by ICMBio/Sisbio (Chico Mendes Institute for Biodiversity Conservation/Authorization and Information on Biodiversity) based on normative instruction number 154/2007 and authorization number 31626-1. 
For drug administration, the animals were divided into six groups of three: the negative control (NC) group, which received saline solution; the group for analysis of biodistribution and plasma kinetics (BPK), whose members were tracked for 24 hours; PTX175 and PTX250, the groups that received the commercial version of the drug in respective concentrations of 175 and $250 \mathrm{mg} / \mathrm{m}^{2}$; and LDE-PTX175 and LDE-PTX250, the groups that received PTX associated with $\mathrm{LDE}$ in respective concentrations of 175 and $250 \mathrm{mg} / \mathrm{m}^{2}$.

After receiving the initial treatment, the animals in the NC, PTX175, PTX250, LDE-PTX175, and LDE-PTX250 groups were tracked during six cycles of intravenous drug administration, at intervals of 3 weeks (21 days) each, for a total of 126 days. During the treatment period, physical and clinical patterns were recorded daily. Three weeks after the last treatment cycle, the animals were euthanized with a lethal dose of sodium pentobarbital, by intravenous injection $(150 \mathrm{mg} / \mathrm{kg})$, and tissue fragments were collected for histopathological analysis.

\section{Clinical evaluation of animals}

Clinical evaluation of the animals was done visually between the hours of 8 and 11 a.m. It was complemented by photographic records and videos to verify any signs of toxicity, such as changes in movement, changes to the skin, fur growth, piloerection, inability to swallow, convulsions, hyperexcitability, abdominal contortions, stereotyped movements, tremors, diarrhea, lethargy, and coma.

\section{Collection of blood samples}

For each of the following experimental procedures and observations (peripheral blood collection, application of LDE-PTX and PTX), the animals were previously sedated by intramuscular injection of $0.2 \mathrm{mg} / \mathrm{kg}$ Zoletil $^{\circledR} 50$ (Tiletamine hydrochloride and Zolazepam hydrochloride).

To perform hematological, biochemical, and LDE plasma kinetics examinations, $5 \mathrm{~mL}$ of blood was collected by venipuncture of the left and/or right femoral artery. The material was divided into vacutainers containing ethylenediamine tetraacetic acid and SST II Advance Gel.

\section{Nanoemulsion preparation and derivitization}

LDEs were prepared from a sequence of dilutions of mother solutions of the lipids that constituted LDE. The lipids were dissolved in a 2:1 solution of chloroform and methanol, using which a mixture of the phospholipids, cholesterol ester, and free cholesterol was prepared (66:33:1). This mixture could be modified according to the results obtained after incorporation with drugs, impelling its use. The process of emulsification and purification of nanoparticles was performed according to the method previously described. ${ }^{18}$ The average size of the nanoparticles was monitored using the laser beam scatter technique. The preparation was then centrifuged at 3,700 rpm for 20 minutes and filtered through a $0.22-\mu \mathrm{m}$ membrane for sterilization. The preparation was stored in sterile, apyrogenic tubes at $4^{\circ} \mathrm{C}$. The PTX was modified and associated with the nanoemulsion by means of cosonication or ultrasonic irradiation. ${ }^{19}$ The final concentration of PTX oleate LDE particles was confirmed by high-performance liquid chromatography (Shimadzu, Kyoto, Japan), which indicated a yield of LDE-PTX particles of $95 \%$. Based on measurements made using a laser-scattering technique, the average particle diameter was $52 \mathrm{~nm}$.

\section{Determination of plasma kinetics and tissue capture of $\left[{ }^{3} \mathrm{H}\right]$-cholesterol ester of LDE}

The radioactivity present in the animals' blood plasma samples was used to trace the plasma decay and to calculate the kinetic parameters of the radioactive lipid components of nanoemulsion. Tracing and calculation were done using version 4.1 of the Anacomp ${ }^{\circledR}$ compartmental analysis software. ${ }^{20}$

The studies of both kinetic behavior and LDE biodistribution were performed on the animals belonging to the BPK group after a 12-hour fast. The animals were previously sedated and injected with about $500 \mu \mathrm{L}$ of LDE oleate PTX (LDE-PTX) marked with $\left[{ }^{3} \mathrm{H}\right]$-free cholesterol in the left femoral vein. Over the course of 24 hours, blood samples were always collected with the animal in a state of sedation at predetermined intervals of time. Samples were taken at 5, 15, and 30 minutes during respective intervals of $1,2,4,6,8,12$, and 24 hours, from the femoral vein (left and/or right). After collection, plasma was separated by centrifuging, and $1 \mathrm{~mL}$ was piped into scintillation test tubes, to which $5 \mathrm{~mL}$ of scintillation solution was added (Ultima Gold XR; PerkinElmer, Waltham, MA, USA).

Twenty-four hours after the injection of LDE marked with radioactive lipids, the following organs and tissues were collected: brain, skin, testicles, seminal vesicles, kidneys, suprarenal glands, spleen, bone marrow, heart, rectus abdominis, psoas muscle, sartorius muscle, diaphragm muscle, liver, lung, stomach, small intestine, large intestine, pancreas, esophagus, bladder, trachea, bile, tongue, fat from the abdominal region, submandibular gland, penis, and lymph nodes. 
Samples of these organs were first selected and cleaned. The tissues were then weighed $(1,000 \mathrm{mg})$ and macerated until they assumed a pasty appearance. The samples were used for extraction of free cholesterol and sterilized according to the method described by Folch et al. ${ }^{21}$

The emitted radioactivity was measured on the liquid scintillation spectrometer after quench correction (Liquid Scintillation Analyzer, 1600TR Tri-Carb; Packard, Ramsey, MN, USA) with version 5.1 of Diamond Computer's Speed STAR Plus software.

\section{Determination of biochemical and hematological profile}

The hematological and biochemical profiles of the animals from the groups NC, LDE-PTX175, LDE-PTX250, PTX175, and PTX250 were determined during all six cycles of chemotherapy (days of drug application or saline solution) as well as during the interval of cycles (on the 14th day) and after the last treatment cycle (21st day).

Biochemical profiles of the nonhuman primates were tracked all throughout the experimental period by analyzing the standard reagents such as alanine aminotransferase (ALT), aspartate aminotransferase (AST), gamma-glutamyl transferase (GGT), urea, creatinine, uric acid, glucose, cholesterol, high-density lipoprotein cholesterol, triglycerides, lipase, alkaline phosphatase, total protein, albumin, globulin, total bilirubin, and calcium using the Architect $5000^{\circledR}$ dry-chemical system (Abbott Diagnostics, Lake Forest, IL, USA), according to the method recommended by the manufacturers of the kits for each parameter analyzed. The hematological analysis, however, was performed using an automatic cell counter for veterinary use (Cell-Dyn Ruby ${ }^{\circledR}$; Abbott Diagnostics).

\section{Pathological and morphological analysis of anatomy}

At the end of treatment, all the animals belonging to groups NC, LDE-PTX175, LDE-PTX250, PTX175, and PTX250 were subjected to euthanasia, whereupon tissue was collected from the following organs for the completion of macroscopic and histopathological examinations: sartorius muscle, psoas muscle, rectus abdominis muscle, diaphragm muscle, heart, submandibular gland, esophagus, tongue, pancreas, small intestine, large intestine, trachea, lung, liver, biliary vesicle, bladder, suprarenal gland, kidney, seminal vesicle, testicles, penis, spleen, lymph nodes, thymus, brain, and skin. This procedure was performed according to the directives established by CONCEA.
Macroscopic analysis of the animals' organs used in this experiment took into consideration the parameters related to consistency, coloration, presence of hemorrhages, and other changes like erosion or visible nodes on various organs.

After collection, the organ fragments and tissues were initially fixed in formalin, packed at a $10 \%$ concentration and with a $\mathrm{pH}$ of 7.2. The next step consisted of sample preparation in a Leica TP 1020 automatic tissue processor. Once impregnated, the tissues were put in molds at room temperature containing molten paraffin and left to harden. Cuts to the blocks were made in a microtome, with a thickness of $6 \mu \mathrm{m}$. Cut tissue was then transferred to a bain-marie kept at $40^{\circ} \mathrm{C}$. Coloration with hemotoxylin $\left(\right.$ Biotec $^{\circledR}$ ) and eosin $\left(\right.$ Synth $\left.^{\circledR}\right)$ was also performed.

\section{Statistical analysis}

The data were expressed as average \pm standard deviation. Comparison between groups was made with a Student's $t$-test and analysis of variance, followed by Bonferroni's multiplecomparison test. Differences were considered statistically significant where $P<0.05$.

\section{Results}

The animals belonging to groups PTX175 and PTX250, which received PTX in its commercial form $\left(\operatorname{Taxol}^{\circledR}\right)$, had severe toxic reactions in their first round of chemotherapy. These were observed clinically as lethargy, convulsions, and hyperemesis. The appearance of these changes, suggestive of a severe toxic reaction, led to the discontinuation of cycles of drug application for four animals, two of which belonged to group PTX175 and two to group PTX250.

\section{Clinical evaluation of animals}

In weight analysis of the animals, only one group, PTX175, presented a weight decline at roughly $28 \%$ of body weight at the end of the experimental period $(2.59 \mathrm{~kg})$, when compared to the control group $(3.57 \mathrm{~kg})$.

In daily clinical evaluation, it was observed that the animals belonging to groups NC, LDE-PTX175, and LDEPTX250 did not present any sign of toxicity or change in behavior. Among the animals in groups PTX175 and PTX250, however, signs of toxicity were found from the second round of chemotherapy onward. These included skin alterations perceivable as flaky inflammatory lesions and progressive weight loss over the course of chemotherapy. As the animals reached the end of the experimental period, they experienced a loss of about $70 \%$ of their body hair. 
Diarrhea and emesis were also observed from the third day following application of the drug.

\section{Analysis of tissue biodistribution and plasma kinetics of nanoemusion in C. apella}

The values of tissue biodistribution of LDE (in BPK group) are expressed in percentage of injected radioactivity per gram of tissue in Figure 2. In general, most organs presented capture levels below 5\%, with the exception of the liver (36.41\%), spleen (6.42\%), and suprarenal gland (7.04\%).

The results observed for plasma kinetics did not show a statistically significant difference between the animals, but instead demonstrated a bioexponential curve. A pattern of rapid initial decay followed by slower subsequent decay was observed as shown in Figure 3. Furthermore, in relation to obtained plasma fractional clearance rate values $(0.0564 \pm 0.0052)$, and to fractional rates of transference $-K_{1,0}(0.429 \pm 0.2275), K_{1,2}(1.0833 \pm 0.33892)$, and $K_{2,0}$ $(0.0346 \pm 0.01188)$, there was no statistical difference between the animals analyzed.

\section{Evaluation of chronic toxicity through determination of hematological and biochemical profile}

The animals from the NC group had normal hematological and biochemical parameters, not presenting a statistically significant difference when compared to normal values found in monkeys of the species C. apella kept in captivity. ${ }^{22,23}$

Of all the values obtained in the analysis of hematological patterns, those that did not present a statistically significant difference among the groups were mean corpuscular volume, mean corpuscular hemoglobin concentration, and eosinophil level. Those analyzed parameters that presented a statistically significant difference among the groups are described in Table 1.

In the analysis of average values of the biochemical profile, it was found that the parameters creatinine, uric acid, calcium, bilirubin, total protein, total albumin, and globulin did not present a statistically significant difference among the groups. The biochemical markers that did present a statistically significant difference among the groups are described in Table 2.

\section{Analysis of pathological and morphological anatomy}

In macroscopic evaluation, significant changes were not found in organs from groups LDE-PTX175 and LDEPTX250. But in group PTX250, which was treated with the largest concentration of the commercial drug, the animals presented the following macroscopic change: congested appearance of lymph nodes and cerebral hemispheres.

In relation to histopathological findings, all animals from all the groups were found to have maintained tissue architecture and integrity of microscopic structures. For example, renal glomeruli, lymphoid follicles, seromucosal

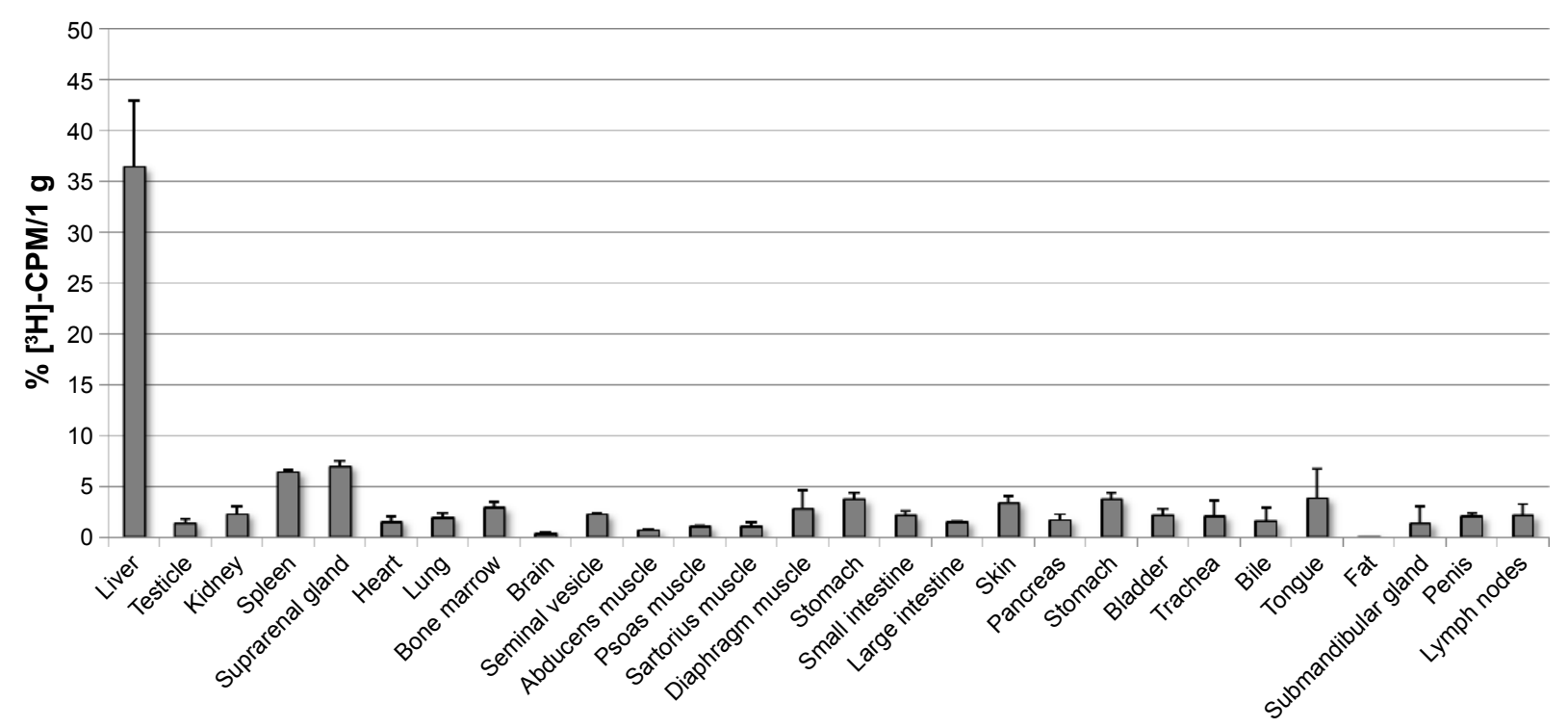

Figure 2 Tissue biodistribution of LDE in Cebus apella, as represented by tissue capture of intravenously injected [ $\left.{ }^{3} \mathrm{H}\right]$-cholesterol ether after 24 hours. The figure shows the evaluation of the radioactivity measured in percentage, and the data are expressed in columns as mean and in bars as standard deviation.

Abbreviations: CPM, counts per minute; LDE, cholesterol-rich nanoemulsion. 


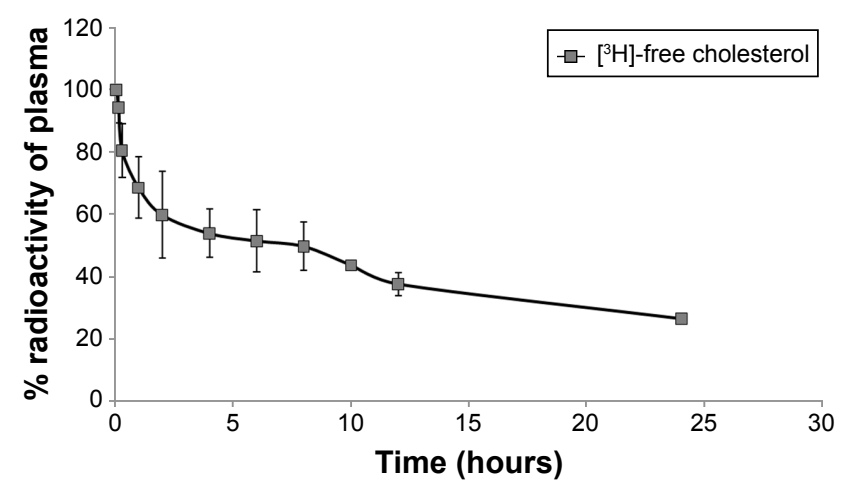

Figure 3 Curve of kinetic decay in plasmatic $\left[{ }^{3} \mathrm{H}\right]$-free cholesterol from LDE in Cebus apella. Points represent mean values and bars represent standard deviation. Abbreviation: LDE, cholesterol-rich nanoemulsion.

salivary glands, chief and parietal cells, gray and white matter, respiratory epithelium, skeletomuscular and cardiac fibers, epidermis, and dermis all remained intact. Changes suggestive of irreversible cellular and tissue damage were not seen in the majority of organs analyzed.

The group LDE-PTX175, which received the lowest concentration $\left(175 \mathrm{mg} / \mathrm{m}^{2}\right)$, behaved in a similar manner as group NC. However, vascular alterations represented by ectasia and hemorrhage were seen in the following organs and tissues: sartorius muscle, psoas muscle, diaphragm and rectus abdominis muscle (two animals), heart (three animals), esophagus, pancreas, and stomach. Lymphoid hyperplasia was even found in two animals from this group. In the spleen, the presence of red-pulp congestion was observed as well as ectasia. In the kidney, however, one of the animals showed important glomerular and tubular hemorrhage, as well as the presence of cylinder hyaline.

Upon analysis of group LDE-PTX250, which received the highest concentration $\left(250 \mathrm{mg} / \mathrm{m}^{2}\right)$, changes of a like nature were observed. These were represented by ectasia and hemorrhage in all skeletomuscular tissues and in the heart, tongue, esophagus, stomach, trachea, biliary vesicle, pancreas, and penis (two animals). These changes, however, presented themselves with a higher frequency and greater intensity when compared to those seen in the LDE-PTX175 group, which received the lowest concentration of LDE-PTX. Aside from these alterations, inflammatory foci were observed in mucosa and submucosa of the stomach, in the lung, and in the kidney (two animals), just as lymphoid hyperplasia was found in the small intestine (three animals). In the liver, one of the animals presented micro- and macrovesicular steatosis with area of fibrosis, as well as sinusoidal hemorrhage, cellular tumefaction, and focal necrosis of hepatocytes. In the same manner, there was red-pulp congestion and ectasia in the spleen. In the kidney, however, one of the animals showed intense glomerular and tubular hemorrhage, vascular congestion, and cylinder hyaline as well as nephrotoxic focal necrosis.

In relation to groups PTX175 and PTX250, histopathological changes in the organs of these animals were found to be similar at the two concentrations studied, which approximated the results seen in group LDE-PTX250 (the latter received LDE-PTX in the highest concentration). In these animals, ectasia and hemorrhage were observed in muscular tissue, heart, esophagus, stomach, lung, and brain. Sinusoidal and

Table I Average values and SDs obtained in analysis of hematological parameters

\begin{tabular}{|c|c|c|c|c|c|}
\hline \multirow[t]{2}{*}{$\begin{array}{l}\text { Hematological } \\
\text { parameters }\end{array}$} & \multirow{2}{*}{$\begin{array}{l}\text { NC } \\
\text { Average } \pm \text { SD }\end{array}$} & \multirow{2}{*}{$\begin{array}{l}\text { LDE-PTX I75 } \\
\left(175 \mathrm{mg} / \mathrm{m}^{2}\right) \\
\text { Average } \pm \text { SD }\end{array}$} & \multirow{2}{*}{$\begin{array}{l}\text { LDE-PTX250 } \\
\left(250 \mathrm{mg} / \mathrm{m}^{2}\right) \\
\text { Average } \pm \text { SD }\end{array}$} & \multirow{2}{*}{$\begin{array}{l}\text { PTX } 175 \\
\left(175 \mathrm{mg} / \mathrm{m}^{2}\right) \\
\text { Average } \pm \text { SD }\end{array}$} & \multirow{2}{*}{$\begin{array}{l}\text { PTX250 } \\
\left(250 \mathrm{mg} / \mathrm{m}^{2}\right) \\
\text { Average } \pm \text { SD }\end{array}$} \\
\hline & & & & & \\
\hline Hematocrit (\%) & $42.72 \pm 1.69$ & $43.80 \pm 2.05$ & $42.80 \pm 3.11$ & $38.96 \pm 2.26^{\mathrm{a}}$ & $4 I .21 \pm 0.49$ \\
\hline Red blood cells $\left(\times 10^{6} \mathrm{~mm}^{3}\right)$ & $5.89 \pm 0.38$ & $5.75 \pm 0.24$ & $5.66 \pm 0.35$ & $5.19 \pm 0.23^{\mathrm{a}}$ & $5.57 \pm 0$ \\
\hline Hemoglobin (G/DI) & $14.2 \pm 0$ & $14.46 \pm 0.28$ & $14.18 \pm 1.06$ & $12.45 \pm\left. 0.2\right|^{b}$ & $13.28 \pm 0.35$ \\
\hline $\mathrm{MCH}(\mu \mathrm{g})$ & $24.4 \pm 1.69$ & $25.12 \pm 0.49$ & $24.98 \pm 0.28$ & $24.13 \pm 1.62^{b}$ & $23.75 \pm 0.70^{\mathrm{b}}$ \\
\hline RDW & $\mid \mathrm{I} .2 \pm 0.2 \mathrm{I}$ & $|1.34 \pm 0.9|$ & $11.50 \pm 1.12$ & $13.38 \pm 1.06^{c}$ & $13 \pm 1.62^{c}$ \\
\hline Leukocytes & $7.91 \pm 4.22$ & $5.26 \pm 1.26^{d}$ & $4.99 \pm 1.73^{d}$ & $5.12 \pm 3.14$ & $5.45 \pm 1.56^{\mathrm{b}}$ \\
\hline Basophils (\%) & $0.63 \pm 0.13$ & $\mathrm{I} .85 \pm 2.0 \mathrm{I}^{\mathrm{d}}$ & $1.17 \pm 1.96$ & $1.28 \pm 0.70$ & $1.55 \pm 2.26$ \\
\hline Neutrophils (\%) & $57.62 \pm 0.84$ & $36.69 \pm 8.34^{d}$ & $40.24 \pm 9.54^{d}$ & $57.39 \pm 17.39^{b}$ & $45.66 \pm 20.01$ \\
\hline Lymphocytes (\%) & $30.07 \pm 0.07$ & $56 \pm 7.28^{e}$ & $54.84 \pm 4.45^{\mathrm{e}}$ & $36.32 \pm 14.56$ & $40.36 \pm 13.08$ \\
\hline Monocytes (\%) & $6.66 \pm 0.96$ & $5.12 \pm 1.08$ & $3.43 \pm 3.31$ & $8.40 \pm 2.12^{c}$ & II $.52 \pm 4.78^{c}$ \\
\hline Platelets $\left(\times 10^{3} / \mathrm{mm}^{3}\right)$ & $238.75 \pm 91.21$ & $\left.2|8.72 \pm 6| .5\right|^{a}$ & $200.93 \pm 21.21$ & $224.83 \pm 7.77^{a}$ & $275.5 \pm 26.16^{b}$ \\
\hline MPV (fL) & $13.4 \pm 0.28$ & $12.32 \pm 0.56$ & $12.36 \pm 0.77$ & $14.56 \pm 0.77^{f}$ & 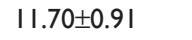 \\
\hline
\end{tabular}

Notes: ${ }^{a} P<0.05$ in relation to group LDE-PTXI75; ${ }^{b} P<0.05$ in relation to groups PTXI75 and LDE-PTX250; ${ }^{c} P<0.05$ in relation to negative control group and groups LDEPTX 175, and LDE-PTX250; ${ }^{d} P<0.05$ in relation to negative control group; ${ }^{e} P<0.05$ in relation to negative control group and groups $P T X 175$, and $P T X 250 ;{ }^{f} P<0.05$ in relation to groups PTX250, LDE-PTXI75, and LDE-PTX250.

Abbreviations: SD, standard deviation; NC, negative control; LDE, cholesterol-rich nanoemulsion; PTX, paclitaxel; MCH, mean corpuscular hemoglobin; RDW, red cell distribution width; MPV, mean platelet volume; g/dL, grams per deciliter. 
Table 2 Average values and SDs obtained in analysis of biochemical parameters

\begin{tabular}{|c|c|c|c|c|c|}
\hline \multirow[t]{2}{*}{$\begin{array}{l}\text { Biochemical } \\
\text { parameters }\end{array}$} & NC & \multirow{2}{*}{$\begin{array}{l}\text { LDE-PTX I } 75 \\
\left(175 \mathrm{mg} / \mathrm{m}^{2}\right) \\
\text { Average } \pm \text { SD }\end{array}$} & \multirow{2}{*}{$\begin{array}{l}\text { LDE-PTX250 } \\
\left(250 \mathrm{mg} / \mathrm{m}^{2}\right) \\
\text { Average } \pm \text { SD }\end{array}$} & \multirow{2}{*}{$\begin{array}{l}\text { PTX I75 } \\
\left(175 \mathrm{mg} / \mathrm{m}^{2}\right) \\
\text { Average } \pm \text { SD }\end{array}$} & \multirow{2}{*}{$\begin{array}{l}\text { PTX250 } \\
\left(250 \mathrm{mg} / \mathrm{m}^{2}\right) \\
\text { Average } \pm \text { SD }\end{array}$} \\
\hline & Average \pm SD & & & & \\
\hline Urea (mg/dL) & $26.66 \pm 16.23$ & $32.61 \pm 9.89^{a}$ & $19.94 \pm 2.50^{\mathrm{b}}$ & $21.25 \pm 5.25$ & $28.33 \pm|| .3 \mid$ \\
\hline Glucose & $66.66 \pm 17.67$ & $63.22 \pm 19.79$ & $74.88 \pm 35.35^{c}$ & $86.4 I \pm 45.25^{c}$ & $106.58 \pm 83.43^{d}$ \\
\hline Cholesterol & $113.00 \pm 28.99$ & $181.25 \pm 23.33$ & $203.08 \pm 18.38^{e}$ & $|66.9| \pm 76.36$ & $|52.75 \pm 1.4|$ \\
\hline HDL-C & $59.66 \pm 5.65$ & $91.30 \pm 1.4 \mathrm{I}^{\mathrm{e}}$ & $92.25 \pm 21.92^{\mathrm{e}}$ & $65.66 \pm 19.79$ & $75.08 \pm 0.70$ \\
\hline Triglycerides & $58.66 \pm 40.30$ & $58.69 \pm 7.77$ & $67.27 \pm 1.4 \mid$ & $77.00 \pm 34.64$ & $104.83 \pm 40.30^{f}$ \\
\hline AST (U/L) & $20.32 \pm 9.71$ & $18.66 \pm 8.65$ & $18.00 \pm 8.58$ & $1 \mathrm{I} .4 \mathrm{I} \pm 3.20^{\mathrm{g}}$ & $14.17 \pm 3.95$ \\
\hline ALT (U/L) & $14.33 \pm 8.02$ & $11.16 \pm 8.13$ & $|2.56 \pm 7.7|$ & $6.75 \pm 1.76^{\mathrm{g}}$ & $6.08 \pm 0.29 g$ \\
\hline GGT (U/L) & $38.67 \pm 20.55$ & $56.50 \pm 26.17$ & $51.47 \pm 28.54$ & $32.08 \pm 8.67^{\mathrm{h}}$ & $67.83 \pm 10.59 c$ \\
\hline Lipase & $22.67 \pm 11.15$ & $17.69 \pm 3.12$ & $19.28 \pm 5.09$ & $14.50 \pm 4.40^{\circ}$ & $13.17 \pm 3.86^{g}$ \\
\hline Alkaline phosphatase & $199.33 \pm 121.33$ & $277.74 \pm 96.85$ & $|4| .64 \pm 53.54 \mid$ & $243.75 \pm 98.75$ & $241.67 \pm 60.91$ \\
\hline
\end{tabular}

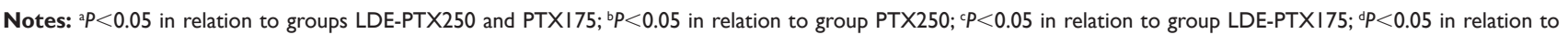
groups LDE-PTXI75, LDE-PTX250, and PTXI75; ${ }^{e} P<0.05$ in relation to group NC; $\mathrm{f}<0.05$ in relation to groups LDE-PTXI75 and LDE-PTX250; 8 P $<0.05$ in relation to groups NC, LDE-PTX175, and LDE-PTX250; ${ }^{\text {P }}<0.05$ in relation to all other groups; $P$ P $<0.05$ in relation to groups NC and LDE-PTX250; $P$ P $<0.05$ in relation to groups LDEPTX175, PTX175, and PTX250.

Abbreviations: SD, standard deviation; NC, negative control; LDE, cholesterol-rich nanoemulsion; PTX, paclitaxel; HDL-C, high-density lipoprotein cholesterol; AST, aspartate aminotransferase; ALT, aspartate aminotransferase; GGT, gamma-glutamyl transferase.

microvesicular steatosis hemorrhages were notable in the liver. In the kidney, glomerular and tubular hemorrhages were notable, as well as cylinder hyaline and the presence of interstitial mononuclear inflammatory cells in these organs.
Red-pulp congestion and ectasia were also seen in the spleen. Finally, there were hemorrhagic foci in the skin.

The results of the histopathological analysis of the tissues and organs studied can be found in Figures 4-6.
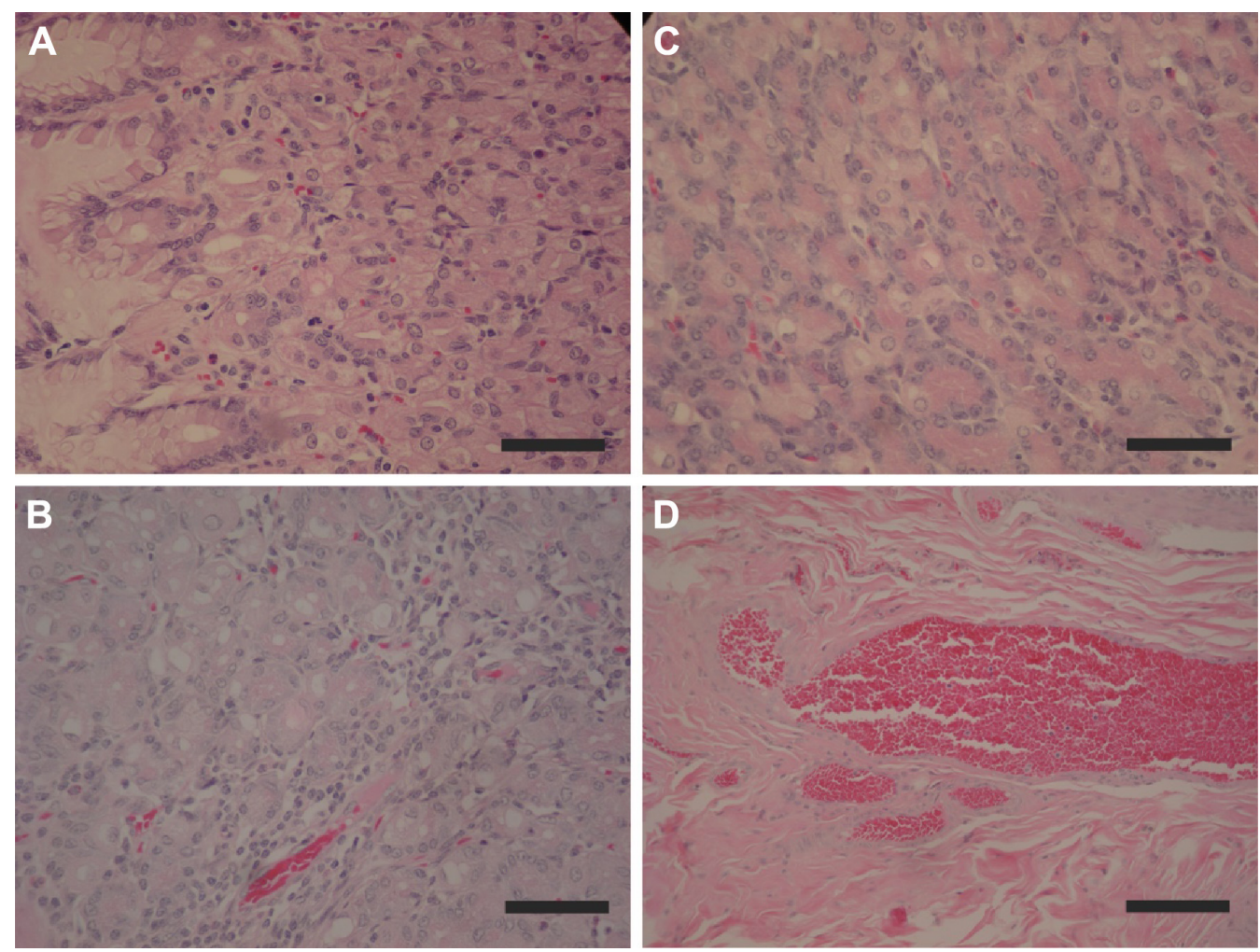

Figure 4 Results of histopathological analysis of the stomach. (A) NC - normal mucosa showing mucoid cells, parietal and chief, and scattered vascular congestion. (B) LDEPTXI75 - normal mucosa showing mucoid cells, parietal and chief, and scattered vascular congestion. (C) LDE-PTX250 - normal mucosa showing mucoid cells, parietal and chief, presenting pervasion by some inflammatory mononuclear cells. (D) LDE-PTX250 - presence of intense vascular congestion in the submucosa. Magnification is $400 \times$, and scale bar represents $50 \mu \mathrm{m}$.

Abbreviations: NC, negative control; LDE, cholesterol-rich nanoemulsion; PTX, paclitaxel. 

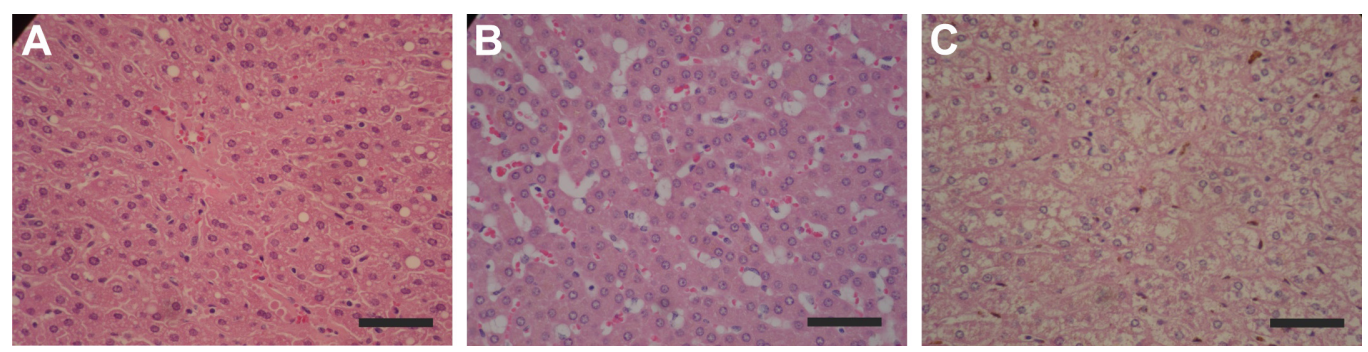

Figure 5 Results of histopathological analysis of the liver. (A) NC - cordons of preserved hepatocytes, seen in the portal space and centrilobular vein, and scattered microvesicular steatosis. (B) LDE-PTXI75 - cordons of preserved hepatocytes, view of de portal space and centrilobular vein, and sinusoidal hemorrhage. (C) LDE-PTX250 disorganization of hepatocyte cordons, hydropic and ballooning degeneration of hepatocytes, and inflammatory foci. Magnification is $400 \times$, and scale bar represents $50 \mu \mathrm{m}$. Abbreviations: NC, negative control; LDE, cholesterol-rich nanoemulsion; PTX, paclitaxel.

\section{Discussion}

The use of vehicles capable of transporting drugs to the target cells has become the object of innumerable studies. These nanoparticles are currently used in preclinical studies with the aim of evaluating the toxicity associated with their use, as has been done with the vehicle LDE. Thus, the present study sought to evaluate, in a broad sense, the toxicity of LDE in nonhuman primates so as to clarify the possible benefits of this particle when it is associated with PTX. Its benefits were compared with those of using the commercial form of this drug, an important step for its future commercial use.

In analysis of the animals' bodily state, we observed that only the animals from the groups treated with commercial PTX presented weight loss, progressive loss of hair, diarrhea, and emesis in the course of treatment. Weight loss in these animals can largely be associated with the probable process of chemotherapy, in which malnutrition, weight loss, nausea, vomiting, and alopecia are common clinical side effects of PTX. ${ }^{24-26}$

Nutritional therapy is of the utmost importance to keep the patient prepared for the aggressive nature of treatment and for his or her bodily restructuring after chemotherapy, because by reducing gastrointestinal side effects and changes in weight, it can contribute satisfactorily to the progress of these patients. ${ }^{27}$

Signs of cutaneous toxicity such as flaky, inflammatory lesions were observed in the groups treated with commercial
PTX from the second cycle of chemotherapy onward. This symptomology has been described in recent studies, which affirmed that signs of cutaneous toxicity are observed in about $65 \%$ of patients subjected to antineoplastic chemotherapy. These alterations include alopecia, hypersensitivity reactions, and alterations to nail tissue. ${ }^{28}$ In the present study, treatment with LDE-PTX did not produce these alterations in animals, demonstrating a possible absence of toxicity in this tissue.

A pharmacokinetic study has demonstrated the characteristic decay of radiotracers in a similar manner as LDL and LDE in other organisms. ${ }^{19}$ The observed plasma kinetics also accorded with those described in previous studies, which demonstrated that associating PTX with LDE changes the pharmacokinetics of the drug as the Cremophor EL-based formulation. The diluent Cremophor EL induces pharmacokinetic alterations that diminish the drug's half-life, ${ }^{10,29}$ while the LDE-PTX preparation has a longer plasmatic half-life $\left(T_{1 / 2}\right)$ and area under the curve. This suggests that the same dose of LDE-PTX remains more highly concentrated for a longer period of time. The therapeutic action of PTX is timedependent, and its capacity to kill cells depends upon the length of exposure. ${ }^{30}$ This being the case, a longer circulation time in the blood - attributable to LDE-PTX - may offer an additional advantage, because it enlarges the drug's spectrum of pharmacological action. ${ }^{10,31}$
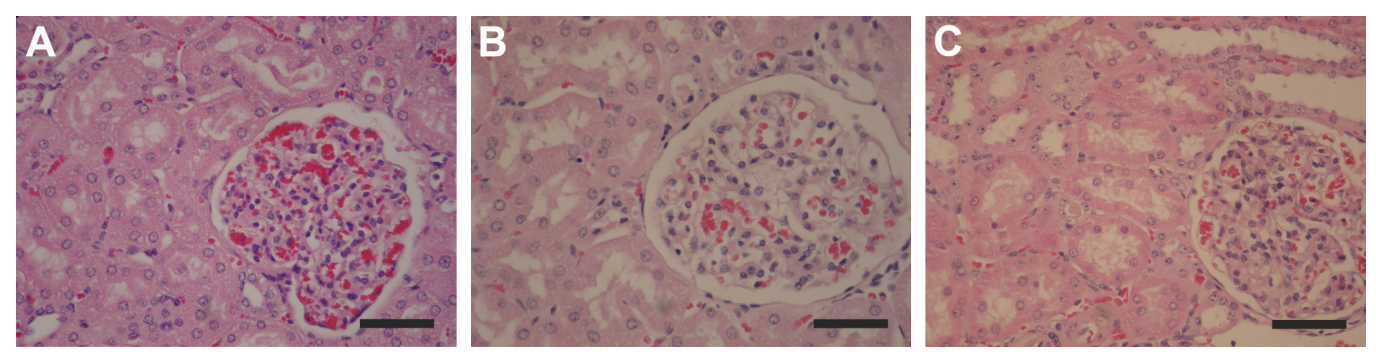

Figure 6 Results of histopathological analysis of the kidney. (A) NC-preserved glomerulus, unaltered proximal and distal tubules, and glomerular and interstitial hemorrhage. (B) LDE-PTXI75 - preserved glomerulus, unaltered proximal and distal tubules, and glomerular and interstitial hemorrhage. (C) LDE-PTX250 - preserved glomerulus, proximal and distal tubes with cellular tumefaction, and glomerular and interstitial hemorrhage, several exhibiting cylinder hyaline. Magnification is $400 \times$, and scale bar represents $50 \mu \mathrm{m}$.

Abbreviations: NC, negative control; LDE, cholesterol-rich nanoemulsion; PTX, paclitaxel. 
Clear comprehension of biodistribution and pharmacokinetics is imperative for the development of drug-delivery systems. Biodistribution of LDE-PTX showed that radioactivity had accumulated in organs with higher quantities of LDLrs. This pattern of accumulation was especially notable in the liver - the main organ related to the metabolism of lipids - and can be taken as confirming the capture of radioactivity by LDLrs. ${ }^{32}$ Another important datum relates to the analysis of a large number of organs, which until now had not been performed. The analysis yielded data that had been heretofore unobserved, such as a low concentration of LDE in bone marrow and in the brain. These findings lead researchers to infer that lower concentrations of PTX oleate LDE in the bone marrow can result in lower levels of meliotoxicity (one of the main side effects of PTX) than those associated with current commercial formulations..$^{33}$

Data from the analysis of erythrogram of groups treated with commercial PTX indicated a possible medicationinduced anemia and a discrete anisocytosis related to the decline of the animals' health due to drug action. ${ }^{34-36}$

In the leukocyte series of animals treated with LDE-PTX, the percentage of neutrophils suffered a decline compared with NC group; however, they were above the acceptable minimum for this species. This differed from the data observed in animals treated with commercial PTX, in which there was a significant decline in the absolute number of neutrophils. By their fifth cycle of chemotherapy, these subjects arrived at an average neutrophil value of 664 cells $/ \mathrm{mm}^{3}$. This value was considered below the acceptable minimum for continuation of treatment. But by the end of the sixth cycle of chemotherapy with commercial PTX, an increase of neutrophils was observed in these animals. Nonetheless, their levels remained below indices of normality. ${ }^{22,37}$

The neutrophil index is used as a parameter for deciding to continue or suspend cycles of antineoplastic chemotherapy, and when the basal count of neutrophils falls below absolute values of 1,000 cells $/ \mathrm{mm}^{3}$, the treatment is suspended or postponed. ${ }^{38,39}$

Lymphocytes in the group treated with LDE-PTX had increased values in comparison with the group treated with the commercial version, showing that the immune systems of animals in the experimental group were not affected in considerable and permanent ways. Instead, their systems remained active without major changes, reinforcing data that the association of LDE with PTX is stable and enables tolerability of treatment. ${ }^{19}$

These data are in agreement with the literature, since the main adverse effects observed in treatment with commercial PTX are the following: adverse reactions relating to the bone marrow (alterations in leucocytes, thrombocytopenia, anemia induced by direct damage to erythrocytes), infections, hypersensitivity to hemorrhage, and neurotoxicity. ${ }^{35,40,41}$

In relation to biochemical parameters, no relationship between PTX dose and alterations in hepatic function was demonstrated in patients without base hepatic alterations. Published research showed only rare relationships to hepatic necrosis and hepatic encephalopathy. ${ }^{42}$ After analysis of biochemical parameters of hepatic function (AST, ALT, and GGT), results obtained in this study showed themselves to be within normal patterns for the species, as much for the groups treated with the commercial form of PTX as for the groups treated with LDE-PTX. This result showed that, despite this particle presenting high affinity to the liver (as observed in biodistribution results for LDE-PTX), it did not demonstrate alterations in hepatic enzymes.

In relation to blood levels of glucose, we observed that they were higher in groups that received the commercial version of PTX, corroborating those previously described. ${ }^{43}$ The authors of that study reported an increase in this parameter in patients who completed polychemotherapy that included PTX. Chemotherapy in patients with diabetes requires precautions, since it has been demonstrated that some drugs can interfere with patients' blood-glucose levels, worsening the control of this disease..$^{44-46}$

Upon observing the results obtained in the plasmatic makeup of lipids, we found a significant difference in cholesterol levels in groups treated with LDE-PTX in relation to those of the NC. These levels, however, were within the normal range for the species $C$. apella, which is between 62.0 and $223.0 \mathrm{mg} / \mathrm{dL}^{23}$

In macroscopic analysis, the majority of organs belonging to animals used in this experiment did not show significant alterations.

Hepatic alterations found in the course of this research, such as sinusoidal hemorrhage, tumefaction of hepatocytes, inflammatory foci, and micro- and macrovesicular steatosis, which were present in all study groups, were of a reversible nature. Many of them can be associated with hepatic metabolism, and thus did not result from the toxic action of PTX. The majority of those histopathological changes that were found are considered of low intensity, reversible, and probably should have arisen from the process of euthanasia and material collection itself. ${ }^{47,48}$

Observed irreversible alterations, such as focal necrosis of hepatocytes in animals treated with LDE-PTX, led us to infer that this alteration may have already been present in these animals before treatment began, as they should not 
have been due to the use of LDE-PTX. Therapeutic doses of PTX did not, however, tend to present hepatic toxicity that compromised the synthesis, storage, and distribution of iron. ${ }^{42}$

In histopathological analysis of the kidneys, intense glomerular and tubular hemorrhages were observed, along with the presence of inflammatory mononuclear cells, and the presence of cylinder hyaline in all groups studied; these microscopic studies, however, did not suggest irreversible alteration of renal function. ${ }^{49}$ Nephrotoxic necrosis was described in one animal from the group treated with the largest concentration of LDE-PTX - an alteration which was also likely to have been present in these animals before the beginning of any treatment in this study and not provoked by LDE-PTX.

There is experimental evidence that a decrease in hepatic LDLrs causes chronic renal failure. ${ }^{50}$ In addition, patients with chronic renal failure have accumulation of plasma lipoproteins. ${ }^{51,52}$ In this study, renal changes observed in some animals are probably due to the accumulation of LDE in plasma, by saturation of LDLrs in the liver caused by the treatment with LDE-PTX.

\section{Conclusion}

The results obtained in the present study suggest that treatment with LDE associated with PTX can reduce the toxicity of this chemotherapy when compared with treatment with the commercial form of this drug. In the group that received LDE-PTX, some clinical manifestations were not observed. Instead, the animals presented an absence of anemia and maintenance of biochemical and hematological patterns considered normal for their species.

\section{Acknowledgments}

The authors would like to specially acknowledge Welligthon Bandeira da Silva of Evandro Chagas Institute-Primate National Center (IEC-CENP) for technical contribution and Marne Carvalho de Vasconcelos of Faculty of Pharmaceutical Sciences of the Federal University of Amazonas for assistance in the design of studies.

\section{Disclosure}

The authors report no conflicts of interest in this work.

\section{References}

1. Gao L, Liu G, Ma J, et al. Paclitaxel nanosuspension coated with P-gp inhibitory surfactants: II. Ability to reverse the drug-resistance of H460 human lung cancer cells. Colloids Surf B Biointerfaces. 2014;117: $122-127$.
2. Liu GX, Fang GQ, Xu W. Dual targeting biomimetic liposomes for paclitaxel/DNA combination cancer treatment. Int J Mol Sci. 2014;15(9): $15287-15303$.

3. Narang AS, Desai DS. Anticancer drug development. Unique aspects of pharmaceutical development. In: Lu Y, Mahato RI, editors. Pharmaceutical Perspectives of Cancer Therapeutics. New York, NY: Springer, LLC; 2009.

4. Yu B, Tai HC, Xue W, Lee LJ, Lee RJ. Receptor-targeted nanocarriers for therapeutic delivery to cancer. Mol Membr Biol. 2010;27(7): 286-298.

5. Kapse-Mistry S, Govender T, Srivastava R, Yergeri M. Nanodrug delivery in reversing multidrug resistance in cancer cells. Front Pharmacol. 2014;5:159.

6. Almeida CP, Vital CG, Contente TC, Maria DA, Maranhão RC. Modification of composition of a nanoemulsion with different cholesteryl ester molecular species: effects on stability, peroxidation, and cell uptake. Int J Nanomedicine. 2010;5:679-686.

7. Gonçalves RP, Rodrigues DG, Maranhão RC. Uptake of high density lipoprotein (HDL) cholesteryl esters by human acute leukemia cells. Leuk Res. 2005;29(8):955-959.

8. Hirata RD, Hirata MH, Mesquita CH, Cesar TB, Maranhão RC. Effects of apolipoprotein B-100 on the metabolism of a lipid microemulsion model in rats. Biochim Biophys Acta. 1999;1437(1):53-62.

9. Azevedo $\mathrm{CH}$, Carvalho JP, Valduga CJ, Maranhão RC. Plasma kinetics and uptake by the tumor of a cholesterol-rich microemulsion (LDE) associated to etoposide oleate in patients with ovarian carcinoma. Gynecol Oncol. 2005;97(1):178-182.

10. Dias ML, Carvalho JP, Rodrigues DG, Graziani SR, Maranhão RC. Pharmacokinetics and tumor uptake of a derivatized form of paclitaxel associated to a cholesterol-rich nanoemulsion (LDE) in patients with gynecologic cancers. Cancer Chemother Pharmacol. 2007;59(1): $105-111$.

11. Hungria VT, Latrilha MC, Rodrigues DG, Bydlowski SP, Chiattone CS, Maranhão RC. Metabolism of a cholesterol-rich microemulsion (LDE) in patients with multiple myeloma and a preliminary clinical study of LDE as a drug vehicle for the treatment of the disease. Cancer Chemother Pharmacol. 2004;53(1):51-60.

12. Maranhão RC, Graziani SR, Yamaguchi N, et al. Association of carmustine with a lipid emulsion: in vitro, in vivo and preliminary studies in cancer patients. Cancer Chemother Pharmacol. 2002;49(6):487-498.

13. Pinheiro KV, Hungria VT, Ficker ES, Valduga CJ, Mesquita CH, Maranhão RC. Plasma kinetics of a cholesterol-rich microemulsion (LDE) in patients with Hodgkin's and non-Hodgkin's lymphoma and a preliminary study on the toxicity of etoposide associated with LDE. Cancer Chemother Pharmacol. 2006;57(5):624-630.

14. Maranhão RC, Garicochea B, Silva EL, Llacer PD, Pileggi FJ, Chamone DA. Increased plasma removal of microemulsions resembling the lipid phase of low-density lipoproteins (LDL) in patients with acute myeloid leukemia: a possible new strategy for the treatment of the disease. Braz J Med Biol Res. 1992;25(10):1033-1037.

15. Maranhão RC, Garicochea B, Silva EL, et al. Plasma kinetics and biodistribution of a lipid emulsion resembling low-density lipoprotein in patients with acute leukemia. Cancer Res. 1994;54(17):4660-4666.

16. Maranhão RC, Tavares ER, Padoveze AF, Valduga CJ, Rodrigues DG, Pereira MD. Paclitaxel associated with cholesterol-rich nanoemulsions promotes atherosclerosis regression in the rabbit. Atherosclerosis. 2008; 197(2):959-966.

17. Takayama S, Thorgeirsson UP, Adamson RH. Chemical carcinogenesis studies in nonhuman primates. Proc Jpn Acad Ser B Phys Biol Sci. 2008; 84(6): 176-188.

18. Maranhão RC, Cesar TB, Pedroso-Mariani SR, Hirata MH, Mesquita CH. Metabolic behavior in rats of a non-protein microemulsion resembling low-density lipoprotein. Lipids. 1993;28(8):691-696.

19. Rodrigues DG, Maria DA, Fernandes DC, et al. Improvement of paclitaxel therapeutic index by derivatization and association to a cholesterol-rich microemulsion: in vitro and in vivo studies. Cancer Chemother Pharmacol. 2005;55(6):565-576. 
20. Lima MF, Pujatti PB, Araújo EB, Mesquita CH. Compartmental analysis to predict biodistribution in radiopharmaceutical design studies. In: 2009 International Nuclear Atlantic Conference - INAC 2009; September 27 to October 2, 2009; Rio de Janeiro.

21. Folch J, Lees M, Sloane-Stanley GH. A simple method for the isolation and purification of total lipides from animal tissues. J Biol Chem. 1957;226(1):497-509.

22. Riviello MC, Wirz A. Haematology and blood chemistry of Cebus apella in relation to sex and age. J Med Primatol. 2001;30(6):308-312.

23. Wirz A, Truppa V, Riviello MC. Hematological and plasma biochemical values for captive tufted capuchin monkeys (Cebus apella). Am J Primatol. 2008;70(5):463-472.

24. Extra JM, Rousseau F, Bruno R, Clavel M, Le Bail N, Marty M. Phase I and pharmacokinetic study of Taxotere (RP 56976; NSC 628503) given as a short intravenous infusion. Cancer Res. 1993;53(5):1037-1042.

25. Slichenmyer WJ, Von Hof DD. Taxol: a new and effective anti-cancer drug. Anticancer Drugs. 1991;2(6):519-530.

26. Wang Y, Wu KC, Zhao BX, et al. A novel paclitaxel microemulsion containing a reduced amount of Cremophor EL: pharmacokinetics, biodistribution, and in vivo antitumor efficacy and safety. $J$ Biomed Biotechnol. 2011;2011:854872.

27. Cuppari L. Guia de nutrição: nutrição clínica no adulto [Guides of Nutrition: Clinical Nutrition for Adults]. 3rd ed. Barueri: Manole; 2009. Portuguese.

28. Schwartz J, Domchek SM, Hwang WT, Fox K. Evaluation of anemia, neutropenia and skin toxicities in standard or dose-dense doxorubicin/ cyclophosphamide (AC)-paclitaxel or docetaxel adjuvant chemotherapy in breast cancer. Ann Oncol. 2005;16(2):247-252.

29. ten Tije AJ, Verweij J, Loos WJ, Sparreboom A. Pharmacological effects of formulation vehicles: implications for cancer chemotherapy. Clin Pharmacokinet. 2003;42(7):665-685.

30. Goble S, Bear HD. Emerging role of taxanes in adjuvant and neoadjuvant therapy for breast cancer: the potential and the questions. Surg Clin North Am. 2003;83(4):943-971.

31. Woo HL, Swenerton KD, Hoskins PJ. Taxol is active in platinum-resistant endometrial adenocarcinoma. Am J Clin Oncol. 1996;19(3):290-291.

32. Favero GM, Maranhão RC, Maria DA, Levy D, Bydlowski SP. Synthetic nanoemulsion resembling a protein-free model of 7-ketocholesterol containing low density lipoprotein: in vitro and in vivo studies. Biol Res 2010;43(4):439-444.

33. Ma P, Mumper RJ. Paclitaxel nano-delivery systems: a comprehensive review. J Nanomed Nanotechnol. 2013;4(2):1000164.

34. Han JJ, Kim YJ, Kim JW, et al. Salvage treatment with low-dose weekly paclitaxel in elderly or poor performance status patients with metastatic urothelial carcinoma. Tumori. 2014;100(4):439-445.

35. Nakamura T, Ueda T, Oishi M, et al. Salvage combined chemotherapy with paclitaxel, ifosfamide and nedaplatin for patients with advanced germ cell tumors. Int J Urol. 2015;22(3):288-293.

36. Hoffbrand AV, Moss PAH, Pettit JE. Fundamentos em hematologia [Fundamentals of hematology]. 6th ed. Porto Alegre: Artmed; 2013. Portuguese.

37. Naves EA, Ferreira FA, Mundim AV, Guimarães EC. Valores hematológicos de macaco prego (Cebus apella - Línnaeus, 1758) em cativeiro [Hematological values of prey monkey (Cebus apella - Línnaeus, 1758) in captivity]. Biosci J. 2006;22(2):125-131. Portuguese [with English abstract].
38. Brandão HN, David JP, Couto RD, Nascimento JAP, David JM. Química e farmacologia de quimioterápicos antineoplásicos derivados de plantas [Chemistry and pharmacology of antineoplastic chemotherapeutics derived from plants]. Quím Nova. 2010;33(6):1359-1369. Portuguese [with English abstract].

39. Hamaguchi T, Matsumura Y, Suzuki M, et al. NK105, a paclitaxelincorporating micellar nanoparticle formulation, can extend in vivo antitumour activity and reduce the neurotoxicity of paclitaxel. $\mathrm{Br} J$ Cancer. 2005;92(7):1240-1246.

40. Siau C, Xiao W, Bennett GJ. Paclitaxel- and vincristine-evoked painful peripheral neuropathies: loss of epidermal innervation and activation of Langerhans cells. Exp Neurol. 2006;201(2):507-514.

41. Panis C, Lemos LG, Victorino VJ, et al. Immunological effects of taxol and adryamicin in breast cancer patients. Cancer Immunol Immunother. 2012;61(4):481-488.

42. Taxol. Technical Manager Dr. Elizabeth M. Oliveira. Package leaflet. Sao Paulo: Bristol-Myers Squibb Farmacêutica S.A.; 2013.

43. Holanda CMCX, Oliveira EH, Rocha LG, et al. Effect of paclitaxel $\left(\right.$ Taxol $\left.^{\circledR}\right)$ on the biodistribution of sodium pertechnetate $\left(\mathrm{Na}^{99 \mathrm{~m}} \mathrm{TcO}_{4}\right)$ in female Wistar rats. Braz Arch Biol Technol. 2008;51(Special Number):191-196.

44. Kratz F, Elsadek B. Clinical impact of serum proteins on drug delivery. J Control Release. 2012;161(2):429-445.

45. Bertato MP, Oliveira CP, Wajchenberg BL, Lerario AC, Maranhão RC. Plasma kinetics of an LDL-like nanoemulsion and lipid transfer to HDL in subjects with glucose intolerance. Clinics (Sao Paulo). 2012; 67(4):347-353.

46. Bonassa EMA, Gato MIR. Enfermagem Em Terapêutica Oncológica [Nursing in Oncology Therapeutics]. 4th ed. Sao Paulo: Atheneu; 2012. Portuguese.

47. Yamauchi H, Feins EN, Vasilyev NV, Shimada S, Zurakowski D, Del Nido PJ. Creation of nonischemic functional mitral regurgitation by annular dilatation and nonplanar modification in a chronic in vivo swine model. Circulation. 2013;128(11 Suppl 1):S263-S270.

48. Calosi P, Turner LM, Hawkins M, et al. Multiple physiological responses to multiple environmental challenges: an individual approach. Integr Comp Biol. 2013;53(4):660-670.

49. Macdougall IC, Cooper AC. Erythropoietin resistance: the role of inflammation and pro-inflammatory cytokines. Nephrol Dial Transplant. 2002;17 (Suppl 11):39-43.

50. Kim C, Vaziri ND. Down-regulation of hepatic LDL receptorrelated protein (LRP) in chronic renal failure. Kidney Int. 2005; 67(3):1028-1032.

51. Nestel PJ, Fidge NH, Tan MH. Increased lipoprotein-remnant formation in chronic renal failure. $N$ Engl J Med. 1982;307(6):329-333.

52. Ron D, Oren I, Aviram M, Better OS, Brook JG. Accumulation of lipoprotein remnants in patients with chronic renal failure. Atherosclerosis. 1983;46(1):67-75.
International Journal of Nanomedicine

\section{Publish your work in this journal}

The International Journal of Nanomedicine is an international, peerreviewed journal focusing on the application of nanotechnology in diagnostics, therapeutics, and drug delivery systems throughout the biomedical field. This journal is indexed on PubMed Central, MedLine, CAS, SciSearch $®$, Current Contents $\AA /$ Clinical Medicine,

\section{Dovepress}

Journal Citation Reports/Science Edition, EMBase, Scopus and the Elsevier Bibliographic databases. The manuscript management system is completely online and includes a very quick and fair peer-review system, which is all easy to use. Visit http://www.dovepress.com/ testimonials.php to read real quotes from published authors. 